\title{
TEACHING COMMUNICATION THEORY AND PRACTICE IN HIGHER EDUCATION
}

\author{
Gaiane Muradian* \\ Yerevan State University
}

Communication is a social phenomenon based on sharing information, ideas and attitudes. Maturity, experience, personal and social relationships that run more smoothly and become more meaningful, are developed, expanded and advanced through communication. Hence, the purpose of this paper based on case study methodology is to help students understand the principles of communication theory/study and put them into practice in life. The skills and techniques learned in the course are essential to effective communication in intrapersonal, interpersonal, small-group and public speaking and can be applied not only through studying the theoretical material but also through practical exercises, discussions and presentations that will enable to incorporate them into daily life and activity. As a result, students will learn to function in a more productive and assertive way in public and work environments and develop the newfound abilities to speak up effectively in other contexts.

Keywords: communication theory and practice, higher education, teaching communication skills and techniques, visuals, videos, PowerPoint presentation.

\section{Introduction}

Communication has existed since the appearance of human beings. In the classical period (300 BC) it was already a topic of great interest (Aristotle, 1908) but was not defined until the $20^{\text {th }}$ century when people began to study the process of communication. Interest in the academic study of communication intensified after World War I as advances in technology and literacy made communication a topic of concern (Littlejohn, 2008). After mid- $20^{\text {th }}$ century when communication was defined as a discipline by S. F. 
Scudder (1980), communication theory/study started focusing on communication as central to human interaction and experience, and involved an understanding of how human beings/entities behave in creating, exchanging, and interpreting messages in their quest for survival (Glory \& Akpan, 2017). Thus, the course of communication theory focuses on human communication, on communication that realizes its functions in human society. Today it plays an important role in Information Technology (IT) and telecommunications as well, strengthening and giving way to less personal and more social interactions in every sphere of human activity. The course must be based on both theoretical and practical approaches as the students need firstly to understand the principles of communication theory, and secondly - put the acquired knowledge into practice by improving their own communication skills through exercising, discussing, presenting. As a result, they will learn to function assertively and in more productive ways in public and work environments and develop the newfound abilities to speak up effectively in a variety of other contexts.

\section{Teaching communication theory}

The course of communication theory fulfills the general education requirement for studying an academic discipline and acquiring core competencies of oral communication. At large, the focus of the course is on teaching what communication is (1) and on practicing skills needed to improve the quality of interpersonal communication in a variety of contexts (2). The core issues to be investigated in the classroom include such topics/themes as the origin and academics of communication, definition of communication, the importance of studying the nature and role of messages in life and society, the communication theory framework, its spheres of investigation, the communication process, barriers to communication and ways to overcome them, cross-cultural communication, speech act theory, characteristics, components, models, types, forms, registers, styles, gender and rhetoric of communication, etc.

At the very beginning of the course students need to be explained that when we communicate, we are trying to establish commonness with someone, that is, we are trying to share information, an idea or an attitude. Students should learn and know that being one of the key concepts in 
linguistics, the term communication has promoted several definitions by linguists, and the idea of sharing the information is the principal one in most definitions. In the broad sense communication refers to "every kind of mutual transmission of information using signs or symbols between living beings (humans, animals), as well as between people and data-processing machines" (Bussman, 1996, p. 83). In the narrow sense communication includes only human beings, and according to C. Hovland (1953), a wellknown psychologist, is the process by which a human individual (the communicator) transmits stimuli (usually verbal symbols) to modify the behavior of other individuals. Encyclopedia Britannica (2020) defines communication as the exchange of information between individuals through a common system of verbal symbols, and, as D. Crystal (1999, p. 62) states, it is "the transmission and reception of information between a signaller and a receiver." If we look at other perceptions of communication defined by communication theorists, we can come across characterizations such as "communication is the generation of meaning" or "communication is a ubiquitous and powerful source in society" (Bowers\&Bradac, 1984, p. 872). I would add here that communication is a social multimodal, multidimensional semiotic system; that is, communication is a resource for meaning across the constantly changing verbal and non-verbal contexts of human interaction, an all-pervading powerful source in society which, along with traditional oral and written discourse modes, today is also realized through numerous other media such as live-streaming and online text messaging, pictures, images, symbols, graphic design, cartoons, colours, music, clothing, theatre-like scenes/actions and other artistic expressions that convey messages (Muradian, 2019). After the disclosure of the essence of communication, the discussions should evolve through analyses and conversations on the above-mentioned topics included in the course.

For example, the students will be explained that to communicate effectively we need to be familiar with the factors involved in the communication process which is usually described along such major dimensions as content - what type of things are communicated, source - by whom, form - in which form, channel - through which medium, destination/receiver - to whom, and purpose - with what kind of results (Berio, 1960; Berko, 2010). Being aware of these factors will help us plan 
and analyze situations, solve problems, and in general, do better no matter what our job might be.

Theoretical explanations and discussions will be accompanied by information listed in bullets, visuals (tables, charts, figures, concept maps, flowcharts, diagrams, infographics) and video materials as they have a far more significant impact on human long-term memory than other communication methods, and engage students more quickly, simplify complex theoretical topics, help them to better process and comprehend the material and finally - facilitate communication. Hence, courses which incorporate suitable visuals gain a higher preference over text-only ones. Below are visuals used when discussing basic communication models:

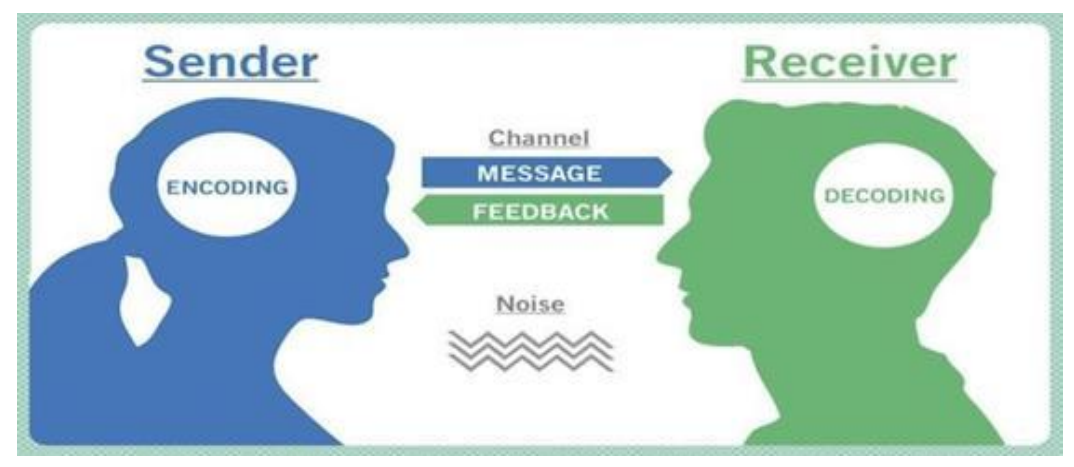

Figure 1. Kobir's communication model

\section{\begin{tabular}{|l|l|l|l|l|l|}
\hline SOURCE & ENCODER & MESSAGE & CHANNEL & DECODER & RECEIVER \\
\hline
\end{tabular}}

Figure 2. Shannon-Weaver model of communication

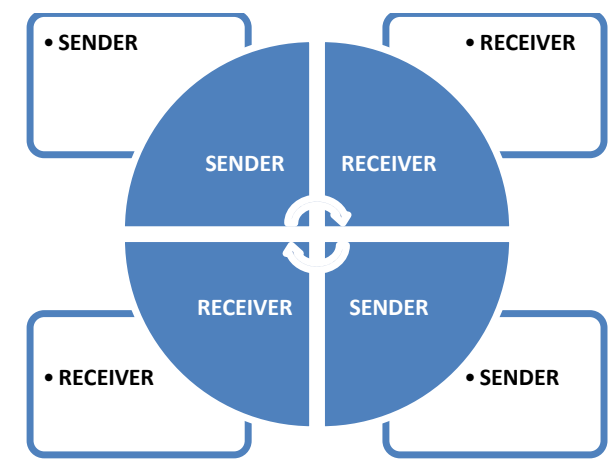

Figure 3. Schramm's communication model 


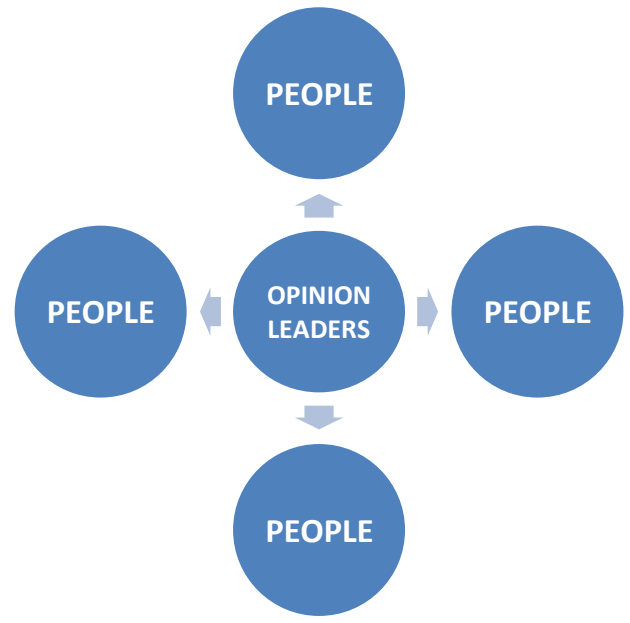

Figure 4. Katz-Lazersfeld communication model

C. Heffner's (2012) communication styles and Aristotle's (1954) triad/rhetorical triangle could be presented by the following infographics:

\begin{tabular}{|c|c|c|c|}
\hline & Passive & Assertive & Aggressive \\
\hline $\begin{array}{c}\text { Definitio } \\
\mathbf{n}\end{array}$ & $\begin{array}{l}\text { Communication style in which you put } \\
\text { the rights of others before your own, } \\
\text { minimizing your own self worth }\end{array}$ & $\begin{array}{l}\text { Communication style in which you stand } \\
\text { up for your rights while maintaining } \\
\text { respect for the rights of others }\end{array}$ & $\begin{array}{l}\text { Communication style in which you } \\
\text { stand up for your rights but you } \\
\text { violate the rights of others }\end{array}$ \\
\hline $\begin{array}{l}\text { Implicat } \\
\text { ions to } \\
\text { Others }\end{array}$ & $\begin{array}{l}\text { my feelings are not important } \\
\text { I don't matter } \\
\text { I think I'm inferior }\end{array}$ & $\begin{array}{l}\text { we are both important } \\
\text { we both matter } \\
\text { I think we are equal }\end{array}$ & $\begin{array}{l}\text { your feelings are not important } \\
\text { you don't matter } \\
\text { I think I'm superior }\end{array}$ \\
\hline $\begin{array}{l}\text { Verbal } \\
\text { Styles }\end{array}$ & $\begin{array}{l}\text { apologetic } \\
\text { overly soft or tentative voice }\end{array}$ & $\begin{array}{l}\text { I statements } \\
\text { firm voice }\end{array}$ & $\begin{array}{l}\text { you statements } \\
\text { loud voice }\end{array}$ \\
\hline $\begin{array}{l}\text { Non- } \\
\text { Verbal } \\
\text { Styles }\end{array}$ & $\begin{array}{l}\text { looking down or away } \\
\text { stooped posture, excessive head nodding }\end{array}$ & $\begin{array}{l}\text { looking direct } \\
\text { relaxed posture, smooth and relaxed } \\
\text { movements }\end{array}$ & $\begin{array}{l}\text { staring, narrow eyes } \\
\text { tense, clenched fists, rigid posture, } \\
\text { pointing fingers }\end{array}$ \\
\hline $\begin{array}{c}\text { Potentia } \\
\text { I } \\
\text { Consequ } \\
\text { ences }\end{array}$ & $\begin{array}{l}\text { lowered self esteem } \\
\text { anger at self } \\
\text { false feelings of inferiority } \\
\text { disrespect from others } \\
\text { pitied by others }\end{array}$ & $\begin{array}{l}\text { higher self esteem } \\
\text { self respect } \\
\text { respect from others } \\
\text { respect of others }\end{array}$ & $\begin{array}{l}\text { guilt } \\
\text { anger from others } \\
\text { lowered self esteem } \\
\text { disrespect from others } \\
\text { feared by others }\end{array}$ \\
\hline
\end{tabular}

Infographic 1. Heffner's communication styles 


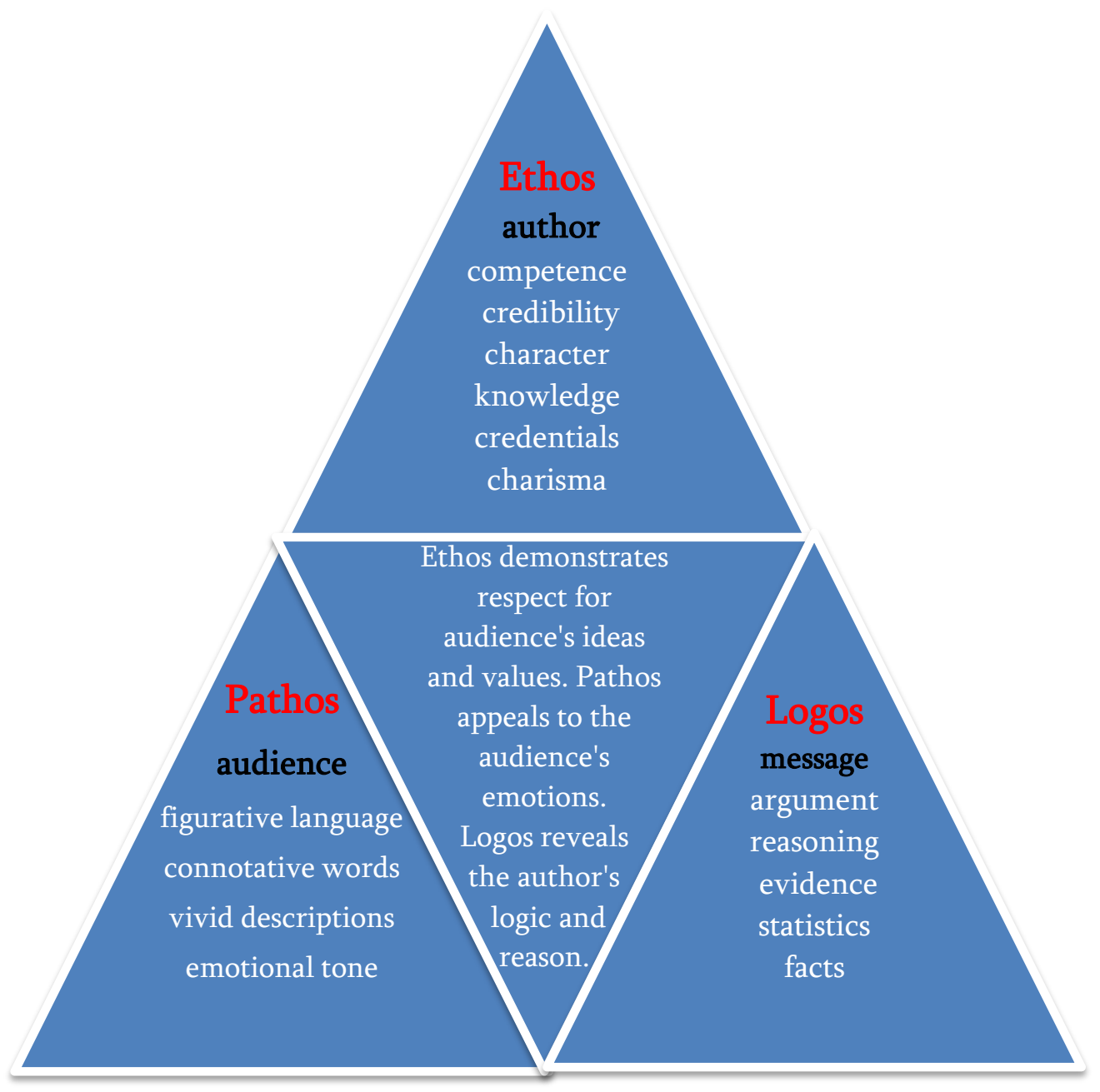

Infographic 2. Aristotle's triad /rhetorical triangle

Today the exponential rise in technology has created many new modes of presenting complex theoretical materials (in our case it is the theory of communication) through new multimodal tools/ mediums and the teacher can choose the most creative ones to make a strong impact on learners and facilitate learning. In other words, visuals are an important aspect of learning a theoretical course that communicate the key concepts and engage learners throughout the course. It should also be noted that the printed theoretical materials and visuals are appropriate both for offline/classroom and online/e-Learning courses. 


\section{Putting communication theory into practice}

In any theoretical course, students are expected to practice comprehension in class. At large, the focus of the course of communication theory is not only on learning but also practicing oral skills needed to improve the quality of interpersonal communication in a variety of contexts, such as in relationships, groups, organizations, public settings, and diverse cultures.

A good practical tool to be used to check the acquired knowledge is the self-check questions to be done in the classroom. For example, after investigating the types of communication, students could discuss self- check questions on verbal, nonverbal, written communication, body language and gesture, paralanguage and electronic culture for literacy and educational reasons. A short YouTube video on the four types of communication (the link given in the self-check questions) will be watched while doing the selfcheck questions. At another lesson the video material will be on types of communication personalities or on testing one's own personality type online. The videos will enable ongoing communication. Other multimodal means include such communication and teaching methodological tools as discussion boards, Prezi or PowerPoint presentations, Screencast-o-Matic video and podcasts. Social media options can also be used to deliver the theoretical content creatively and meaningfully. Discussions, disputes, presentations should be encouraged during the whole process of teaching the course. Diverse audio and video tools support students in learning best by hearing. For different assignments visuals and videos that generate conversation are good tools. Mind maps can provide the structure for a productive brainstorming session. For example, after investigating crosscultural norms of communication, independent/interdependent cultures in which language plays a great role (Kiuchi 2006) and high-context/lowcontext cultures (Hall, 1973; Ramos, 2014; Bai, 2016), it is a good idea to put down the topic of high- and low-context cultures in the middle of the map and ask the students to identify their own culture's place in it and discuss their ideas related to this issue. 


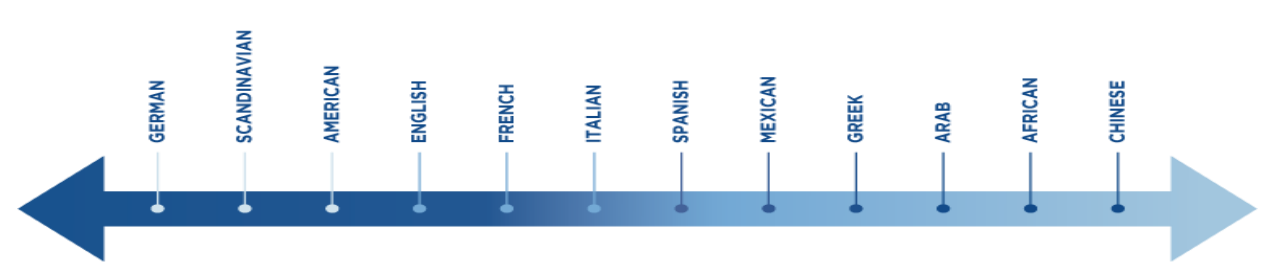

LOW - CONTEXT CULTURES

HIGH - CONTEXT CULTURES

Figure 5. High and low context culture map

Generation of an active discussion among the students on topics like the one on high and low cultures will help students memorize the theoretical material and get involved in active conversation developing their oral communication skills.

Another practical communication tool to be used in lectures (both by teachers and students) is the Microsoft PowerPoint - probably the bestknown presentation graphics program available. The presentations made by students help animate the ideas they have trouble understanding and allow ample time for questioning and discussing. Students usually use advanced designs/communication skills and demonstrate superb research presentations based on the given lecture. The presentation topics (in our case Culture Influence on Interpersonal Communication; Relational Communication; Interpersonal Communication in Virtual Reality; Communication in Social Conflict; Artifacts in Intercultural Information Exchange; Leadership Communication Style, etc.) are assigned by the teacher. Such presentations are usually interactive, contain text, art, animation and audio and video elements. They present graphically enhanced information and instruction to the whole class, keep the students interested in the topic and encourage an active discussion thus contributing to the comprehension and absorption of the academic material and development of communication skills.

\section{Conclusion}

Today new technologies are introducing many changes to mass communication and communication theories which must be developed or revised to keep up with the changes in virtual/electronic or computer 
mediated communication. This means communication theorists will have to shift to models and theories that recognize the interactivity of the $21^{\text {st }}$ century media. Academic lectures based on the convergence of the course of communication theory and technology tend to encourage both the comprehension of the discipline and development of communication skills. Captivating visuals, engaging videos, attractive infographics motivate learners to do better; help them grasp concepts easily by stimulating imagination and affecting their cognitive capabilities (they have the potential "to stretch" the human mind and memory when absorbing, comprehending, analyzing, discussing, presenting). The mentioned tools add value to the theoretical course material and should meet the requirements of simplifying the not-easy-to-understand material, encouraging interactive communication, helping learners connect the familiar materials with the unfamiliar. Hence, the key is to use visuals and videos effectively to add value to an academic course and draw learners to both offline and online education platforms.

Summing up, it should be mentioned that each of us has our own experiences and perspectives to draw upon from the communication theory course, thus creating an ongoing application of human communication in general. Every student is encouraged to actively join and contribute to this dialogue as we explore the fascinating field of communication.

\section{References}

Aristotle. (1908). Interpretation. The works of Aristotle. In W. D. Ross \& J.A. Smith (Eds.). Historia Animalium. Oxford: Claredon.

Aristotle. (1954). Rhetoric and Poetics. New York: Random House.

Bai, H. A. (2016). Cross-cultural analysis of advertisements from highcontext cultures to low-context cultures. English Language Teaching, 9 (8), 21-30. doi:10.5539/elt.v9n8p21

Berio, D. (1960). The process of communication. New York: Holt, Rinehart, and Winston.

Berko, R. (2010). Communicating. Boston, MA: Pearson Education.

Bowers, J. W., \& Bradac, J. (1984). Contemporary problems in human communication theory. Boston: Allyn and Bacon. 
Bussman, H. (1996). Routledge dictionary of language and linguistics. London, NY: Routledge.

Crystal, D. (1999). The Penguin dictionary of language. London: Penguin Books.

Encyclopedia Britannica. In Britannica online (2020). Retrieved from https://britannica.com.au/britannica-online

Glory, A. \& Akpan, K. (2017). Influence of student-teacher communication on students' academic achievement for effective teaching and learning. American Journal of Educational Research, 5(10), 11021107. doi: 10.12691/education-5-10-12

Heffner, C. L. (2012). Communication styles. Retrieved from http://facultyevaluation.org/meta/communication_styles.htm.

Hall, E. T. (1973). The silent language. New York: Anchor.

Hovland, C., Janis, I. L., \& Kelley, H. H. (1953) Communication and persuasion: psychological studies of opinion change. New Haven: Yale UP.

Kiuchi, A. (2006). Independent and interdependent self-construals: Ramifications for a multicultural society. Japanese Psychological Research, 48/1, 1-16.

Kobir, L. (2019). The nine components of communication process. Retrieved from https://newsmoor.com/the-nine-components-of-communication-process/

Littlejohn, S. W., \& Foss, K. A. (2008). Theories of human communication. Belmont, CA: Thomson Wadsworth.

Scudder, S. F. (1980). Communication theory as a universal law. Retrieved from https://en.mwikibooks.org

Muradian, G. (2019). Breaking communication stereotypes: the discourse of Armenian velvet revolution. British Journal of Education, Society and Behavioural Science, 30 (2), 1-7. DOI:10.9734/JESBS/2019/v30i230123

Ramos, C. (2014). High context. Low context. Encyclopedia of Diversity and Social Justice. Rowman \& Littlefield Publishers. 


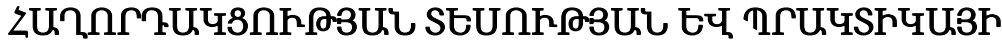

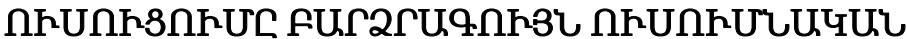

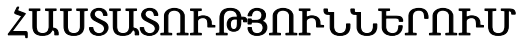

\section{Qujuilt Unıpựuiq}

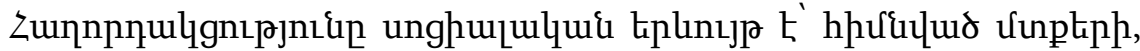

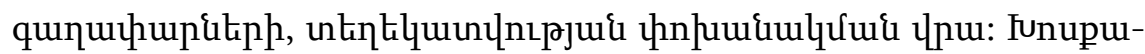

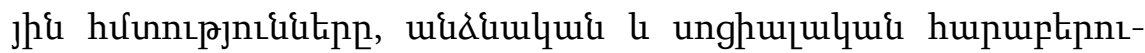

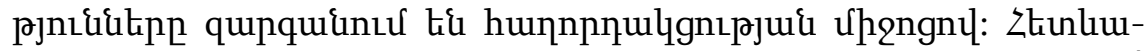

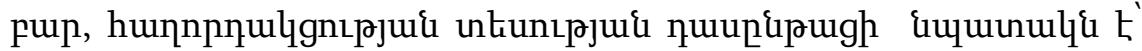

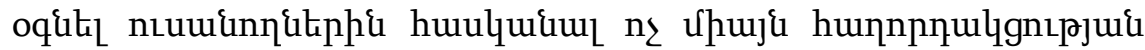

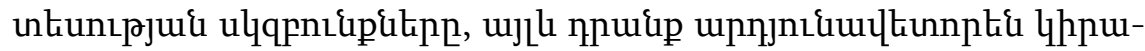

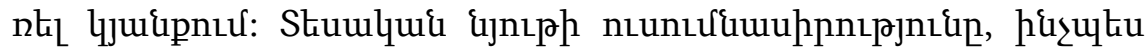

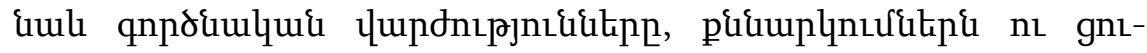

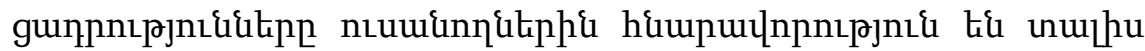

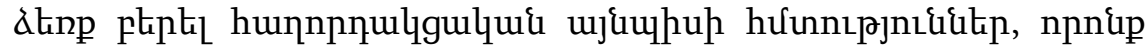

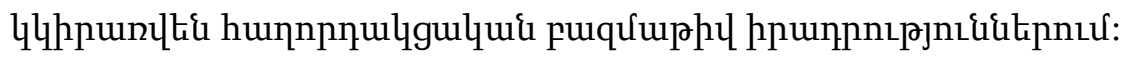

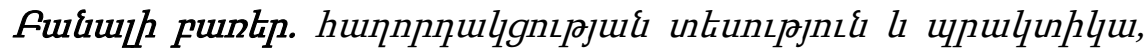

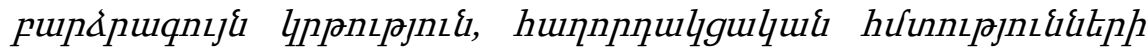

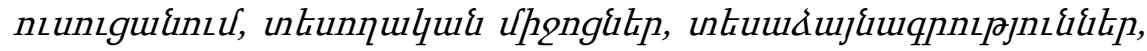
PowerPoint \&lipluujugnul: 